\title{
Mortality from heart disease in a cohort of 23,000 patients with insulin-treated diabetes
}

\author{
S. P. Laing1 , A. J. Swerdlow ${ }^{1}$, S. D. Slater ${ }^{2}$, A. C. Burden ${ }^{3}$, A. Morris ${ }^{4}$, N. R. Waugh ${ }^{5}$, W. Gatling 6 , \\ P. J. Bingley ${ }^{7}$, C. C. Patterson 8 \\ ${ }^{1}$ Section of Epidemiology, Brookes Lawley Building, Institute of Cancer Research, Sutton, Surrey SM2 5NG, UK \\ ${ }^{2}$ Strathclyde Diabetic Group, Victoria Infirmiary, Glasgow, UK \\ ${ }^{3}$ University of Leicester, Leicester, UK \\ ${ }^{4}$ RCPE Diabetic Registry Group, University of Dundee, Dundee, UK \\ 5 Scottish Study Group for the care of diabetes in the young, University of Aberdeen, Aberdeen, UK \\ 6 Poole Hospital NHS Trust, Poole, UK \\ ${ }^{7}$ University of Bristol, Bristol, UK \\ ${ }^{8}$ The Queen's University of Belfast, Belfast, UK
}

\begin{abstract}
Aims/hypothesis. Although ischaemic heart disease is the predominant cause of mortality in older people with diabetes, age-specific mortality rates have not been published for patients with Type 1 diabetes. The Diabetes UK cohort, essentially one of patients with Type 1 diabetes, now has sufficient follow-up to report all heart disease, and specifically ischaemic heart disease, mortality rates by age.

Methods. A cohort of 23,751 patients with insulintreated diabetes, diagnosed under the age of 30 years and from throughout the United Kingdom, was identified during the period 1972 to 1993 and followed for mortality until December 2000. Age- and sex-specific heart disease mortality rates and standardised mortality ratios were calculated.

Results. There were 1437 deaths during the follow-up, 536 from cardiovascular disease, and of those, 369
\end{abstract}

from ischaemic heart disease. At all ages the ischaemic heart disease mortality rates in the cohort were higher than in the general population. Mortality rates within the cohort were similar for men and women under the age of 40 . The standardised mortality ratios were higher in women than men at all ages, and in women were 44.8 (95\% CI 20.5-85.0) at ages 20-29 and $41.6(26.7-61.9)$ at ages 30-39.

Conclusions/interpretation. The risk of mortality from ischaemic heart disease is exceptionally high in young adult women with Type 1 diabetes, with rates similar to those in men with Type 1 diabetes under the age of 40. These observations emphasise the need to identify and treat coronary risk factors in these young patients. [Diabetologia (2003) 46:760-765]

Keywords Type 1 diabetes, insulin-dependent diabetes, cohort study, ischaemic heart disease, mortality.
Cardiovascular disease (CVD) has been recognised as a complication of diabetes in older patients for many decades [1,2], with mortality from CVD and especially from ischaemic heart disease (IHD) exceeding that

Received: 21 October 2002 / Revised: 17 February 2003

Published online: 28 May 2003

(C) Springer-Verlag 2003

Corresponding author: Dr. S. P. Laing, Section of Epidemiology, Brookes Lawley Building, Institute of Cancer Research, Cotswold Road, Sutton, Surrey SM2 5NG, UK

E-mail: slaing@icr.ac.uk

Abbreviations: SMR, Standardised mortality ratio; IHD, ischaemic heart disease; CVD, cardiovascular disease. in the general population. Within the past 30 years there have been a number of studies quantifying the risk of IHD mortality but these have been mainly restricted to patients with Type 2 diabetes $[3,4,5,6]$ or have included patients with Type 1 and Type 2 diabetes together [7,8]. Although CVD is also recognised as a complication in patients with Type 1 diabetes [9, 10], mortality from IHD has been less frequently studied and IHD mortality risks by age and sex have not been reported for these patients.

If the high CVD mortality is to be addressed clinically it is necessary to investigate the various components of CVD separately. The Diabetes UK Cohort Study (formerly BDA Cohort Study) [11, 12] has 
followed over 23,000 patients with insulin-treated diabetes, diagnosed under the age of 30 years, and now has sufficient follow-up to examine IHD mortality in detail and compare the results with data from studies of patients with Type 2 diabetes.

\section{Subjects and Methods}

The Diabetes UK Cohort and its follow-up has been described in detail elsewhere $[11,12]$. A total of 23,751 patients with insulin-treated diabetes diagnosed under the age of 30 years were recruited into the cohort between 1972 and 1993 from all parts of the United Kingdom.

The study was approved by the institutional review board appropriate at the time the cohort was established. The earliest registers began recruiting incident cases in 1972, but the majority of the cases, both incident and prevalent, were recruited from 1982 onwards. Patients with diabetes secondary to other conditions were excluded from the cohort at the outset, or in a few cases following notification of diagnosis from the death certificate. Although insulin treatment rather than insulin dependency was the criterion for inclusion, this cohort was essentially one of patients with Type 1 diabetes. The patients were all diagnosed under the age of 30 years and, based on the distribution of diabetes type by age at diagnosis [13], we estimate that at least $94 \%$ were Type 1 .

Details of the patients were sent to the National Health Service Central Registers for patients from England, Scotland and Wales, and to the Central Services Agency for patients from Northern Ireland, who notified us of all deaths and emigrations. For the present analyses follow-up was until the end of December 2000. Death certificates were obtained for the subjects who died and cause of death was coded to the International Classification of Diseases (ICD) revision in force at the time of death [14]. For heart disease overall the ICD9 codes were 391-398, 402, 404-429 and for ischaemic heart disease we used the ICD9 codes 410-414, 429.2. Equivalent ICD8 and ICD10 codes were used for the relevant years. As deaths coded to the underlying cause 'diabetes' (ICD9 code 250) might reflect a range of short term metabolic or long term degenerative complications, the other registered causes of death were examined in those cases and all cardiovascular and renal deaths were recoded to the relevant categories.

For each cohort member, person-years at risk by age group, sex, calendar year and country of residence at registration were calculated from the date of registration to either 31 December
2000 or the date of death, $85^{\text {th }}$ birthday, emigration or other loss to follow-up if earlier. Mortality within the cohort from all types of heart disease and ischaemic heart disease alone were compared with corresponding mortality in the general population in a number of ways. Age-specific rates were calculated and were compared with general population age-specific mortality rates, using Scottish national rates as the comparison for the patients from Scotland and Northern Ireland, and rates for England and Wales as the comparison for the rest. Standardised mortality ratios (SMRs), were calculated as the ratio of the number of observed deaths to the number of expected deaths. The absolute excess risk (AR) a measure of the excess mortality in patients with diabetes in additive terms, was calculated by subtracting the expected from the observed number of deaths and dividing by the person-years. Expected deaths were calculated separately for each calendar year by multiplying the age-, sex-, and country-specific person-years at risk in the cohort by the corresponding mortality rates for that specific calendar year for the general population of England and Wales (for the English and Welsh patients) and Scotland (for the Scottish and Northern Irish cases). The expected deaths and observed numbers of deaths were totalled for the whole period of follow-up. Ninety-five per cent confidence intervals were calculated using the Poisson distribution [15]. A $p$ value of 0.05 was considered statistically significant.

\section{Results}

The 23,751 patients who entered the cohort were followed for up to 29 years. In total the subjects contributed 404,073 person-years of follow-up, an average of 17 years per subject. By the end of December 2000 a total of 1437 deaths from all causes occurred and 128 patients emigrated. Of the total deaths, 536 were from diseases of the cardiovascular system, including 424 from heart disease and 80 from cerebrovascular disease. Of the heart disease deaths, 369 (230 in men, 139 in women) were classified specifically to IHD. As a proportion of deaths in the cohort, IHD accounted for $8 \%$ of deaths under age 40 years and $47 \%$ of deaths at older ages in men, and $11 \%$ and $40 \%$ of deaths for the same age groups in women.

Mortality rates from IHD are compared with rates in the general population (Table 1). At each age group

Table 1. Mortality rates from ischaemic heart disease in cohort members and the general population by sex and age

\begin{tabular}{|c|c|c|c|c|c|c|}
\hline \multirow{2}{*}{$\begin{array}{l}\text { Attained age, } \\
\text { years }\end{array}$} & \multicolumn{3}{|l|}{ Males } & \multicolumn{3}{|l|}{ Females } \\
\hline & $\begin{array}{l}\text { No. of deaths } \\
\text { in cohort }\end{array}$ & $\begin{array}{l}\text { Rate in cohort } \\
\text { patients }^{\mathrm{a}}\end{array}$ & $\begin{array}{l}\text { Rate in general } \\
\text { population }^{\mathrm{a}}\end{array}$ & $\begin{array}{l}\text { No. of deaths } \\
\text { in cohort }\end{array}$ & $\begin{array}{l}\text { Rate in cohort } \\
\text { patients }^{\mathrm{a}}\end{array}$ & $\begin{array}{l}\text { Rate in general } \\
\text { population }\end{array}$ \\
\hline $10-19$ & 1 & 1 & 0 & 1 & 1 & 0 \\
\hline $20-29$ & 9 & 12 & 1 & 9 & 14 & 0 \\
\hline $30-39$ & 24 & 69 & 9 & 24 & 84 & 2 \\
\hline $60-69$ & 58 & 2790 & 776 & 34 & 1855 & 312 \\
\hline $70-84$ & 23 & 4281 & 1982 & 27 & 5027 & 946 \\
\hline $1-84$ & 230 & 107 & 24 & 139 & 73 & 8 \\
\hline
\end{tabular}

a Rate per 100,000 person-years 


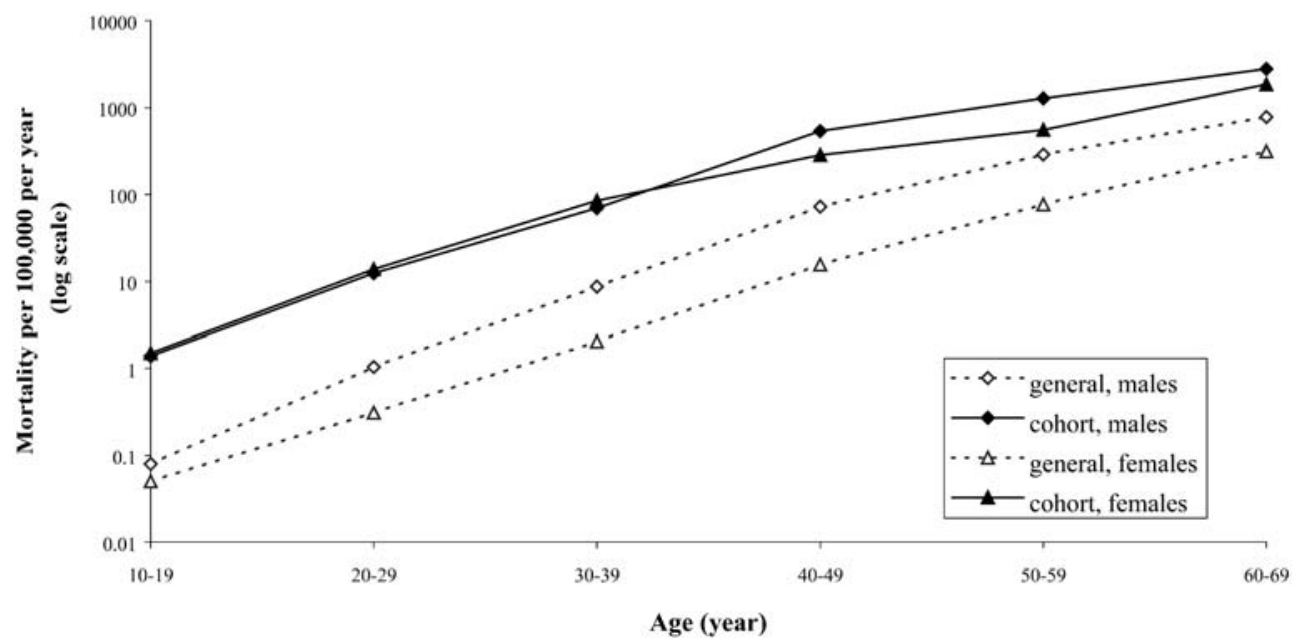

Fig. 1. Ischaemic heart disease mortality rates in the cohort and in the general population

Table 2. Relative and absolute excess risks of mortality from ischaemic heart disease in cohort members by age and sex

\begin{tabular}{|c|c|c|c|c|c|c|}
\hline \multirow{2}{*}{$\begin{array}{l}\text { Attained age, } \\
\text { years }\end{array}$} & \multicolumn{3}{|l|}{ Males } & \multicolumn{3}{|l|}{ Females } \\
\hline & $\operatorname{SMR}^{\mathrm{a}}(95 \% \mathrm{CI})$ & $\mathrm{AR}^{\mathrm{b}}$ & $\begin{array}{l}\% \text { of IHD deaths } \\
\text { attributable } \\
\text { to diabetes }\end{array}$ & $\operatorname{SMR}^{\mathrm{a}}(95 \% \mathrm{CI})$ & $\mathrm{AR}^{\mathrm{b}}$ & $\begin{array}{l}\% \text { of IHD deaths } \\
\text { attributable } \\
\text { to diabetes }\end{array}$ \\
\hline $10-19$ & $17.0(0.4-94.4)$ & 1 & 94 & $27.8(0.7-154.8)$ & 10 & 97 \\
\hline $20-29$ & $11.8(5.4-22.4) * * *$ & 11 & 92 & $44.8(20.5-85.0) * * *$ & 13 & 98 \\
\hline $50-59$ & $4.4(3.4-5.7) * * *$ & 986 & 77 & $7.2(4.5-10.9) * * *$ & 474 & 86 \\
\hline $60-69$ & $3.6(2.7-4.7) * * *$ & 2014 & 72 & $5.9(4.1-8.3)^{* * *}$ & 1544 & 83 \\
\hline $70-84$ & $2.2(1.4-3.2) * *$ & 2299 & 54 & $5.3(3.5-7.7) * * *$ & 4081 & 81 \\
\hline $1-84$ & $4.5(3.9-5.1) * * *$ & 83 & 77 & $8.8(7.4-10.3) * * *$ & 65 & 89 \\
\hline
\end{tabular}

a Standardised mortality ratio

b Absolute excess risk per 100,000 person-years

\section{$* * p<0.01$}

$* * * p<0.001$ the mortality rates for the patients with Type 1 diabetes were higher than the corresponding rates for subjects in the general population. The mortality rates in the females with Type 1 diabetes were not only greater than for women without diabetes but were also considerably higher than for men without diabetes (Fig. 1). In the general population mortality from IHD was much higher in men than women at all adult ages, but in patients with Type 1 diabetes there was no difference between men and women in IHD mortality rates under the age of 40 years $(p=0.64)$. At ages 40 to 84 years overall the rate was higher in men than women $(p=0.001)$ but less so, in proportionate terms, than in the general population.

This greatly increased vulnerability of the younger women with Type 1 diabetes is shown in the standardised mortality ratios and absolute excess risks for the patients with diabetes (Table 2). At all ages the SMRs were higher for women than men, reflecting both the high mortality rates from IHD among the women with diabetes and the comparatively low mor- tality rates, especially at younger ages, among women in the general population. In the 20 to 29 age group a woman with Type 1 diabetes was 45 times more likely to die of IHD than a woman of similar age without diabetes, and in the 30 to 39 age group the risk was still increased over forty times.

For direct comparison with other studies the SMRs were also calculated for all patients under the age of 60 , and for the 45 to 64 age group. In the under $60 \mathrm{~s}$ the SMRs were $6.0(5.1-7.1)$ for men and 15.4 (12.1-19.2) for women. The SMRs for the 45 to 64 age group were $4.7(3.9-5.6)$ for men and 7.9 (5.9-10.4) for women.

In terms of absolute excess risk the increase in IHD mortality was greater in men than women between the ages of 40 to 69 , but was greater in women at older ages (Table 2). The percentage of IHD deaths attributable (in a statistical sense) to diabetes was $89 \%$ in men and $98 \%$ in women under the age of 40 years, and although this percentage declined with age, even at ages 60 to 69 years $72 \%$ of the IHD 
Table 3. Mortality rates and standardised mortality ratios for ischaemic and other types of heart disease in cohort members by age and sex

\begin{tabular}{|c|c|c|c|c|c|c|c|c|c|}
\hline \multirow[t]{2}{*}{ Cause of death } & \multirow{2}{*}{$\begin{array}{l}\text { Attained } \\
\text { age, } \\
\text { years }\end{array}$} & \multicolumn{4}{|l|}{ Males } & \multicolumn{4}{|c|}{ Females } \\
\hline & & $\begin{array}{l}\text { No. } \\
\text { of } \\
\text { deaths }\end{array}$ & $\begin{array}{l}\text { Rate } \\
\text { in } \\
\text { cohort }^{a}\end{array}$ & $\begin{array}{l}\text { Rate } \\
\text { in gen. } \\
\text { pop. }^{a}\end{array}$ & SMR $(95 \%$ CI $)$ & $\begin{array}{l}\text { No. } \\
\text { of } \\
\text { deaths }\end{array}$ & $\begin{array}{l}\text { Rate } \\
\text { in } \\
\text { cohort }^{\mathrm{a}}\end{array}$ & $\begin{array}{l}\text { Rate } \\
\text { in gen. } \\
\text { pop. }^{a}\end{array}$ & SMR $(95 \%$ CI $)$ \\
\hline Ischaemic heart disease & $\begin{array}{r}1-39 \\
40-84\end{array}$ & $\begin{array}{r}34 \\
196\end{array}$ & $\begin{array}{r}17.3 \\
1115.2\end{array}$ & $\begin{array}{r}1.9 \\
271.3\end{array}$ & $\begin{array}{l}8.9(6.2-12.9)^{* * *} \\
4.1(3.6-4.7)^{* * *}\end{array}$ & $\begin{array}{r}34 \\
105\end{array}$ & $\begin{array}{r}19.4 \\
741.0\end{array}$ & $\begin{array}{l}0.5 \\
106\end{array}$ & $\begin{array}{c}41.7(28.9-58.2)^{* * * *} \\
7.0(5.7-8.4)^{* * *}\end{array}$ \\
\hline All heart disease & $\begin{array}{r}1-39 \\
40-84\end{array}$ & $\begin{array}{r}52 \\
210\end{array}$ & $\begin{array}{r}26.4 \\
1194.9\end{array}$ & $\begin{array}{r}4.0 \\
301.7\end{array}$ & $\begin{array}{l}6.6(5.0-8.7) * * * \\
4.0(3.4-4.5) * * *\end{array}$ & $\begin{array}{r}48 \\
114\end{array}$ & $\begin{array}{r}27.4 \\
804.5\end{array}$ & $\begin{array}{r}1.6 \\
129.2\end{array}$ & $\begin{array}{c}17.1(12.6-22.7)^{* * * *} \\
6.2(5.1-7.5)^{* * *}\end{array}$ \\
\hline
\end{tabular}

a Rate per 100,000 person-years; $* * p<0.01 ; * * * p<0.001$

deaths in men and $83 \%$ in women were attributable to diabetes.

There was also a raised risk of mortality, as recorded on the death certificate, from other types of heart disease (Table 3 ). This category included hypertensive heart disease, valvular disorders, cardiomyopathy, dysrhythmias and heart failure. At young ages the SMR was again higher for females than males, but after the age of 40 the SMRs were similar in the two sexes. There was no difference in mortality rates between the sexes in either the under 40 age group ( $p=0.7)$ or the 40 and over age group $(p=0.6)$.

The SMRs were calculated separately for patients with the underlying cause of death recorded as cardiomyopathy and patients with death recorded as either hypertensive heart disease or heart failure. The SMR was not raised in either age group for death from cardiomyopathy; for men it was $2.8(0.7-7.1)$ in the 1 to 39 age group and $1.1(0.0-6.0)$ in the 40 to 84 age group, and for women it was $4.8(0.6-17.3)$ in the 1 to 39 age group with no deaths from cardiomyopathy in the older group. The SMR was raised for deaths from hypertensive heart disease and heart failure in those aged 1 to 39 years ( 9.4 (1.9-27.4) for men and 39.1 (12.7-91.2) for women), but was not raised at older ages [2.5 (0.7-6.4) for men and $3.3(0.7-9.7)$ for women].

\section{Discussion}

Although an increased risk of heart disease is well recognised as a chronic complication of diabetes, agespecific mortality statistics for death from IHD have not been previously reported in patients with Type 1 diabetes, perhaps because published cohorts have been too small $[9,10,16]$. We have shown that in patients with Type 1 diabetes IHD mortality rates are raised in comparison with the general population at all adult ages, and in both sexes.
Although there are no age-specific results to compare with the findings reported here, a few studies of patients with Type 1 diabetes have reported overall mortality or morbidity from IHD. Comparison with these must be cautious, however, because of differences in the specific endpoints or in the age and sex distribution of the study patients. For example, the Nurses Health Study Cohort [3] (which looked at Type 1 and Type 2 patients separately) reported fatal and non-fatal events grouped together, and the WHO Multinational Study [17, 18, 19] has reported incidence rates, by sex, of new IHD events in patients with insulin-dependent diabetes, but only expressed mortality as the number of IHD deaths as a percentage of the total.

A more direct comparison can be made with the results from a population-based study from Wisconsin [16]. This recorded SMRs for IHD mortality in a group of 1200 patients with Type 1 diabetes diagnosed under the age of 30 years, but the results were not subdivided by age. They reported SMRs for IHD mortality at ages under 60 years of 9.1 for males and 13.5 for females. In our study, the SMRs for the patients at ages under 60 were 6.0 for men and 15.4 for women. The exceptionally high SMRs in the younger women in our data were only apparent after finer stratification by age.

Comparison can also be made with studies of patients with Type 2 diabetes, bearing in mind the limitations mentioned previously, and that, particularly in European populations, Type 2 diabetes is overwhelmingly a disorder of later life. In all reports IHD mortality was raised in patients with Type 2 diabetes compared with the non-diabetic population $[3,4,5,6,8$, $16,20,21]$. The data were not usually stratified by age, possibly because in the main the average age of the patients was over 50 years at the beginning of follow-up. Generally, the relative risks were higher in women than men, but one study [8] reported SMRs of 2.7 in men and only 1.2 in women for IHD mortality in the 40 to 65 age group, and the Wisconsin Study 
[16] reported similar SMRs in both sexes of 2.4 in men and 2.2 in women. In the studies of IHD mortality that have reported higher SMRs in women than men, the SMRs in men have ranged from 1.8 to 3.7 whereas those in women have ranged from 2.2 to 9.2 $[3,4,6,20,21]$.

Of all these previously reported studies of patients with Type 2 diabetes, perhaps the best comparison with our data is a cohort study from Scotland [20]. Not only was this from a geographical area included in our cohort but the age at which the patients died was also specified. This study followed 4186 patients with predominantly Type 2 diabetes and reported SMRs for IHD mortality in the 45 to 64 age group of 3.7 for men and 5.4 in women. SMRs from our study of patients aged 45 to 64 years were only slightly higher -4.7 in men and 7.9 in women.

In the absence of epidemiological studies of IHD in young patients with Type 2 diabetes, direct comparisons cannot be made with those age groups, but it should be noted from our data that in patients with Type 1 diabetes the relative risk of IHD mortality was much higher in the younger than older age groups, although the absolute risk remains low at this age. To some extent this high relative risk is due to the very low rates of mortality from IHD in the general population. This cardioprotection normally afforded to young women is reduced in women with Type 1 diabetes, perhaps because diabetes is present before the menopause. As the incidence of Type 2 diabetes seems to be increasing at the younger ages it will be interesting to note whether younger women developing Type 2 diabetes will also have some loss of cardioprotection.

Among the older patients with Type 1 and Type 2 diabetes the relative risks of IHD death are usually higher in women than men, but the IHD mortality rates remain much higher in men. At younger ages, however, this is not the case and the results reported here for patients with Type 1 diabetes show that mortality rates under the age of 40 years are the same for men and women. Although there are no previous data for mortality, this accords with incidence data from Pittsburgh [22] in which similar rates of new coronary artery disease events were found in males and females under 40 years with Type 1 diabetes, and from the WHO Study [17] which showed similar incidence rates for new myocardial infarctions in men and women with Type 1 diabetes, but higher incidence rates in men than women with Type 2 diabetes.

It is interesting to note that for other types of heart disease the SMRs were also raised, although not raised to the same extent as for IHD, and in both the general population and the cohort the mortality rates were similar for men and women. This suggests that the cardioprotection afforded to women in the general population applies only to protection from ischaemic disease, and it is this, specifically, which is lost or reduced in patients with diabetes. Diabetes is a known risk factor for atherogenesis which could explain the specificity of the relationship.

A study of this nature is dependent on the classification of underlying cause on the death certificate, as we have no access to the individual case notes, and there are a number of heart conditions which are not included within the ICD rubric for IHD but which could have had some degree of ischaemic disease as their basis; in particular, deaths from hypertensive heart disease and heart failure. It was interesting to note in this study, although based on small numbers, that the SMRs for deaths from cardiomyopathy were not raised, whereas the SMRs for death from hypertensive heart disease and heart failure were raised in the under 40 age group. If hypertensive heart disease and heart failure were to have been considered with IHD the SMRs would have been virtually unchanged in the under 40 age groups and slightly diminished (but still raised) in the 40 to 84 age groups. A high frequency of congestive heart failure among young women with diabetes was noted more than a quarter of a century ago in the Framingham Study [23]. Although this is attributed to specific diabetic cardiomyopathy by some, it is regarded by many as a complication of IHD [24].

The absolute number of people dying from IHD in Western countries as a consequence of Type 2 diabetes is greater than for Type 1 because the former is the predominant type of diabetes amongst older people and IHD mortality is related to age. Our data, however, show that in terms of relative risks the impact of Type 1 diabetes is probably greater than that of Type 2, though this could be due to the earlier occurrence rather than the clinical type of diabetes. This study has highlighted the very high relative risks in young women with Type 1 diabetes due to the still unexplained loss of the cardioprotection enjoyed by young women without diabetes. In the meantime these observations serve to emphasise the vital need to identify and treat known coronary risk factors in young people with diabetes.

Acknowledgements. We thank the many individuals who worked to assemble the registers from which the cohort was identified. We recognise with thanks the roles of Drs. A. Bloom, D.R. Gamble and T.M. Hayes in compilation of the original British Diabetic Association register, and the input of physicians throughout the UK who contributed data to that register. We thank the physicians who compiled the other registers, and in addition to those authors who are named we thank Dr J.L. Botha for the Leicester register, Dr.R.D. Hill for the register from Poole, Professor E.A.M. Gale for the register from Oxford and Dr A.W.M. Smith on behalf of the Royal College of Physicians of Edinburgh Diabetic Registry Group. We are grateful to Ms. B. Peachey, Ms. D. Carson, and Mr. C. Wale who worked on assembly of the cohort and data processing, to $\mathrm{Mr} \mathrm{Z}$. Qiao for the statistical analyses, to the NHSCRs and the CSA for follow-up information, and to Professor J. Fuller, Professor V. Hawthorne, Professor H. Keen and Dr. M. Murphy for advice.

The study was funded by Diabetes UK, and the Medical Research Council. 


\section{References}

1. Garcia MJ, McNamara PM, Gordon T, Kannel W (1974) Morbidity and mortality in diabetics in the Framingham population. Diabetes 23:105-111

2. Kannel WB, McGee DL (1979) Diabetes and cardiovascular disease: the Framingham Study. JAMA 241:2035-2038

3. Manson JE, Colditz GA, Stampfer MJ et al. (1991) A prospective study of maturity-onset diabetes mellitus and risk of coronary heart disease and stroke in women. Arch Intern Med 151:1141-1147

4. Stamler J, Vaccaro O, Neaton JD, Wentworth D (1993) Diabetes, other risk factors, and 12-year cardiovascular mortality for men screened in the Multiple Risk Factor Intervention Trial. Diabetes Care 16:434-445

5. Krowlewski AS, Czyzyk A, Janeczkod et al. (1977) Mortality from cardiovascular disease among diabetics. Diabetologia 13:345-350

6. Laakso M, Ronnemaa T, Lehto S, Puukka P, Kallio V, Pyorala K (1995) Does NIDDM increase the risk for coronary heart disease similarly in both low- and high-risk populations? Diabetologia 38:487-493

7. Kessler II (1971) Mortality experience of diabetic patients. A twenty six year follow-up. Am J Med 51:715-724

8. Kleinman JC, Donahue RP, Harris MI, Finucane FF, Madans JH, Brock DB (1988) Mortality among diabetics in a national sample. Am J Epidemiol 128:389-401

9. Dorman JS, Laporte RE, Kuller LH et al. (1984) The Pittsburgh insulin-dependent diabetes mellitus (IDDM) morbidity and mortality study. Mortality results. Diabetes 33:271-276

10. Green A, Hougaard P (1984) Epidemiological studies of diabetes mellitus in Denmark: 5. Mortality and causes of death among insulin-treated diabetic patients. Diabetologia 26:190-194

11. Laing SP, Swerdlow AJ, Slater SD et al. (1999) The British Diabetic Association Cohort Study, I: all-cause mortality in patients with insulin-treated diabetes mellitus. Diab Med 16:459-465

12. Laing SP, Swerdlow AJ, Slater SD et al. (1999) The British Diabetic Association Cohort Study, II: cause-specific mortality in patients with insulin-treated diabetes mellitus. Diab Med 16:466-471
13. Laakso M, Pyorala K (1985) Age of onset and type of diabetes. Diab Care 8:114-117

14. World Health Organisation (1977) Manual of the international statistical classification of diseases, injuries and causes of death. World Health Organisation, Geneva

15. Breslow NE, Day NE (1987) Statistical methods in cancer research. The design and analysis of cohort studies, vol 2. IARC, Lyon, No. 82

16. Moss SE, Klein R, Klein BEK (1991) Cause-specific mortality in a population-based study of diabetes. Am J Pub Health 81:1158-1162

17. Morrish NJ, Stevens LK, Head J, Fuller JH, Keen H, Jarrett RJ (1990) A prospective study of mortality among middleaged diabetic patients (the London cohort of the WHO Multinational Study of Vascular Disease in Diabetics) I: causes and death rates. Diabetologia 33:538-541

18. Morrish NJ, Stevens LK, Fuller JH, Keen H, Jarrett RJ (1991) Incidence of macrovascular disease in diabetes mellitus: the London cohort of the WHO Multinational Study of Vascular Disease in Diabetics. Diabetologia 34:584-589

19. Morrish NJ, Wang SL, Stevens LK, Fuller JH, Keen H (2001) Mortality and causes of death in the WHO Multinational Study of Vascular Disease in Diabetes. Diabetologia 44 (Suppl 2):S14-21

20. Wong JSK, Pearson DWM, Murchison LE, Williams MJ, Narayan V (1991) Mortality in diabetes mellitus: experience of a geographically defined population. Diab Med $8: 135-139$

21. Barrett-Connor EL, Cohn BA, Wingard DA, Edelstein SLE (1991) Why is diabetes mellitus a stronger risk factor for fatal ischaemic heart disease in women that in men? The Rancho Bernardo Study. JAMA 265(5):627-631

22. Lloyd CE, Kuller LH, Ellis D, Becker DJ, Wing RR, Orchard TJ (1996) Coronary artery disease in IDDM. Gender differences in risk factors but not risk. Arterioscler Thromb Vasc Biol 16:720-726

23. Kannel WB, Hjortland M, Castelli WP (1974) Role of diabetes in congestive heart failure: the Framingham Study. Am J Cardiol 34:29-34

24. Grundy SM, Benjamin IJ, Burke GL et al. (1999) Diabetes and cardiovascular disease. Circulation 100:1134-1146 